Article

\title{
Efficient Enzymatic Hydrolysis of Biomass Hemicellulose in the Absence of Bulk Water
}

\author{
Shaghayegh Ostadjoo ${ }^{1}$, Fabien Hammerer ${ }^{1}$ (D), Karolin Dietrich ${ }^{2}$, Marie-Josée Dumont ${ }^{2}$, \\ Tomislav Friscic $1, *(1)$ and Karine Auclair ${ }^{1, *}$ \\ 1 Department of Chemistry, McGill University, 801 Sherbrooke Street West, Montreal, Quebec, H3A 0B8, \\ Canada; shaghaayegh@gmail.com (S.O.); fabien.hammerer@gmail.com (F.H.) \\ 2 Bioresource Engineering Department, McGill University, 21111 Lakeshore Road, Ste-Anne de Bellevue, \\ Quebec, H9X 3V9, Canada; karolin.dietrich@mail.mcgill.ca (K.D.); marie-josee.dumont@mcgill.ca (M.-J.D.) \\ * Correspondence: tomislav.friscic@mcgill.ca (T.F.); karine.auclair@mcgill.ca (K.A.); \\ Tel.: +1-514-398-3959 (T.F.); +1-514-398-2822 (K.A.)
}

Academic Editors: Vjekoslav Štrukil and Matej Baláž

check for updates

Received: 31 August 2019; Accepted: 16 November 2019; Published: 20 November 2019

\begin{abstract}
Current enzymatic methods for hemicellulosic biomass depolymerization are solution-based, typically require a harsh chemical pre-treatment of the material and large volumes of water, yet lack in efficiency. In our study, xylanase (E.C. 3.2.1.8) from Thermomyces lanuginosus is used to hydrolyze xylans from different sources. We report an innovative enzymatic process which avoids the use of bulk aqueous, organic or inorganic solvent, and enables hydrolysis of hemicellulose directly from chemically untreated biomass, to low-weight, soluble oligoxylosaccharides in $>70 \%$ yields.
\end{abstract}

Keywords: hemicellulose; xylan; hemicellulase; xylanase; mechanochemistry; mechanoenzymology; solvent-free; glycosyl hydrolase; saccharification; biowaste

\section{Introduction}

The depletion of petroleum resources and increasing awareness of the impact of the petrochemical industry on the environment have motivated research efforts aiming to exploit sustainable feedstocks, including biowaste valorization. Lignocellulosic biomass is the most abundant biowaste, with $>10^{12}$ tons generated annually [1], and has been proposed as a sustainable fossil fuel replacement alternative [2]. The efficient deployment of biomass-based technologies is however challenged by the highly inert nature of its polymeric constituents [3], the breakdown of which is a necessary step to the exploitation of biomass as a resource [2].

Vascular plant biomass is mainly composed of cellulose, hemicellulose, and lignin. At $20-30 \%$ of the total dry weight of plants, hemicellulose is the second most abundant biopolymer on Earth [4]. Xylan, the main type of hemicellulose, is a vast group of branched heteropolysaccharides, which principally consists of $\beta$-1,4-linked xylose units, with side branches of $\alpha$-arabinofuranose, $\alpha$-glucuronic acids, or other monosaccharides [2,5].

The chemical degradation of biomass xylans produces mainly xylose and xylooligosaccharides [6]. It is usually achieved by exposing the biomass to aggressive chemicals such as acids or bases at high temperature and pressure, with the generation of undesirable side products [7-10], which are preferably removed before further processing [11-13].

Alternatively, numerous bacteria and fungi have naturally evolved to efficiently use lignocellulosic biomass as a source of nutrients [14]. These microorganisms are incapable of transporting the large biopolymers inside the cells. Instead, they secrete a mixture of enzymes, which work at the interface between the solid biomass and moist air to break down the polymers into small soluble oligomers 
and monomers that are next transported inside the cell and metabolized [8]. The xylan component is degraded under ambient conditions by hydrolytic enzymes called xylanases [15,16].

Whereas in vitro hydrolysis of xylans by xylanases in solution has been demonstrated, this strategy necessitates harsh chemical pre-treatment of the biomass in order to expose the hemicellulose, large volumes of water to create a suspension or slurry, and still suffers from low hydrolysis rates and turnover numbers [17-21].

Recent studies by our group, and others [22-32], have established that enzymes can function very well without bulk organic or aqueous solvent. In particular, our group has demonstrated that in the absence of bulk water, cellulases can efficiently catalyze cellulose hydrolysis to glucose $[29,30]$, and chitinases can favor the clean depolymerization of chitin to $N$-acetylglucosamine [31]. Our unconventional approach combines techniques from solvent-free mechanochemistry [33], such as ball milling [34-36] and accelerated aging [37,38], with enzymatic catalysis. While mechanical processing of lignocellulose has been used for decades [39,40], the idea that gentle ball milling can promote enzyme activity is recent and has shown great potential. In contrast to the established methods in enzymology, we report here that xylanase can be more efficient in the absence of bulk aqueous solvent. This is consistent with the natural environment of xylanases, and provides an innovative, efficient way to hydrolyze xylans from biomass directly, without needing chemical pre-treatment or bulk water, thus generating minimal waste. Instead of using bulk water, the herein presented methodology operates under conditions resembling liquid-assisted grinding (LAG), [41-43] in which reactant solubility is not a significant factor and where minuscule amounts of a liquid phase are utilized to accelerate or direct chemical transformations.

\section{Results and Discussion}

We opted to use xylanase from Thermomyces lanuginosus (E.C. 3.2.1.8) because it is available commercially as a lyophilized powder, mostly as a single protein (which was confirmed by electrophoresis, Figure S1) and is stable at temperatures up to $80^{\circ} \mathrm{C}$ [44]. The commercial powder was found to have an extremely low protein content $(0.4 \% w / w$ measured by classical Bradford assay), with the rest of the mixture likely consisting of buffer salts, lyoprotectants, and/or growth medium. In the remainder of this manuscript, enzyme loading will be described as the mass of protein per total initial solid mass used, i.e., the combined mass of the substrate and of the enzyme preparation. The enzymatic reactions reported herein proceed either via ball milling with or without subsequent aging (static incubation) at $55^{\circ} \mathrm{C}$, or via multiple cycles of milling and aging-a process known as reactive aging (RAging) [29-32]. Unless mentioned otherwise, milling was performed at $30 \mathrm{~Hz}$ and room temperature, in $10 \mathrm{~mL}$ teflon jars containing two stainless steel balls ( $7 \mathrm{~mm}$ in diameter). A variety of substrates were investigated, including purified xylans from birchwood and oat spelt, as well as raw sugarcane bagasse and wheat straw biomass.

As a hydrolytic enzyme, xylanase catalyzes the reaction between xylans and water. Herein, except for control reactions in solution (Table 1), water is present in amounts too low to be considered a bulk solvent (moist solid mixture), playing the role of a substrate and also additive that accelerates mechanochemical reactions. The amount of water is conveyed as a ratio of the volume of liquid added in $\mu \mathrm{L}$, to the weight of all solids used in $\mathrm{mg}$, and abbreviated as $\eta$ [42]. The optimal $\eta$ for xylanase was found to be $0.6 \mu \mathrm{L} / \mathrm{mg}$ with purified xylans, and $1 \mu \mathrm{L} / \mathrm{mg}$ with raw biomass (Figures S2 and S3), which correspond to initial mixtures with the consistence of sticky solids. Our enzymatic reactions are therefore defined as liquid-assisted (defined as $\eta<2$ ) [42], or solvent-less rather than solutions or suspensions.

Consistent with the established behavior of enzymes in solution, the percent hydrolysis of xylans observed after milling only, or after milling followed by aging, was found to raise with an increase in enzyme loading, and the optimal value differed with each substrate (Figure S4). Reducing the milling frequency from $30 \mathrm{~Hz}$ to $10 \mathrm{~Hz}$ was detrimental to the yield, with a $\%$ decrease when milling only, 
and a $20 \%$ lower yield when milling is followed by aging (Figure S5). This is most likely due to poorer sample mixing. All subsequent experiments were performed at $30 \mathrm{~Hz}$.

Kinetic studies of the xylanase $(0.08 \%$ protein loading $w / w)$ were performed after a brief period of milling ( $5 \mathrm{~min}$ ) followed by aging, with regular sampling over time. The hydrolysis yield was approximated using the 3,5-dinitrosalicylic acid (DNS) assay [45] and plotted over time. With purified xylan substrates (Figure 1A), a typical hyperbolic behavior was obtained, reaching a plateau after ca. $20 \mathrm{~h}$, at approximately $50 \%$ hydrolysis. The initial rate of the reaction was $2-3 \mu \mathrm{M} / \mathrm{min}$ (Figure 1C).

We next turned to substrates directly obtained from the agricultural industry: Raw sugarcane bagasse and wheat straw samples of known xylan content $(19.9 \%$ and $22.3 \%$, respectively). Both substrates were milled briefly for $10 \mathrm{~min}$ before use, in order to reduce particle size below $1 \mathrm{~mm}$. They were used directly without chemical pre-treatment. The depolymerization of biomass (Figure 1B) during aging after milling for $5 \mathrm{~min}$, proceeded with a higher initial rate $(11-12 \mu \mathrm{M} / \mathrm{min})$ and to a better yield $(>60 \%)$ than with purified xylans.

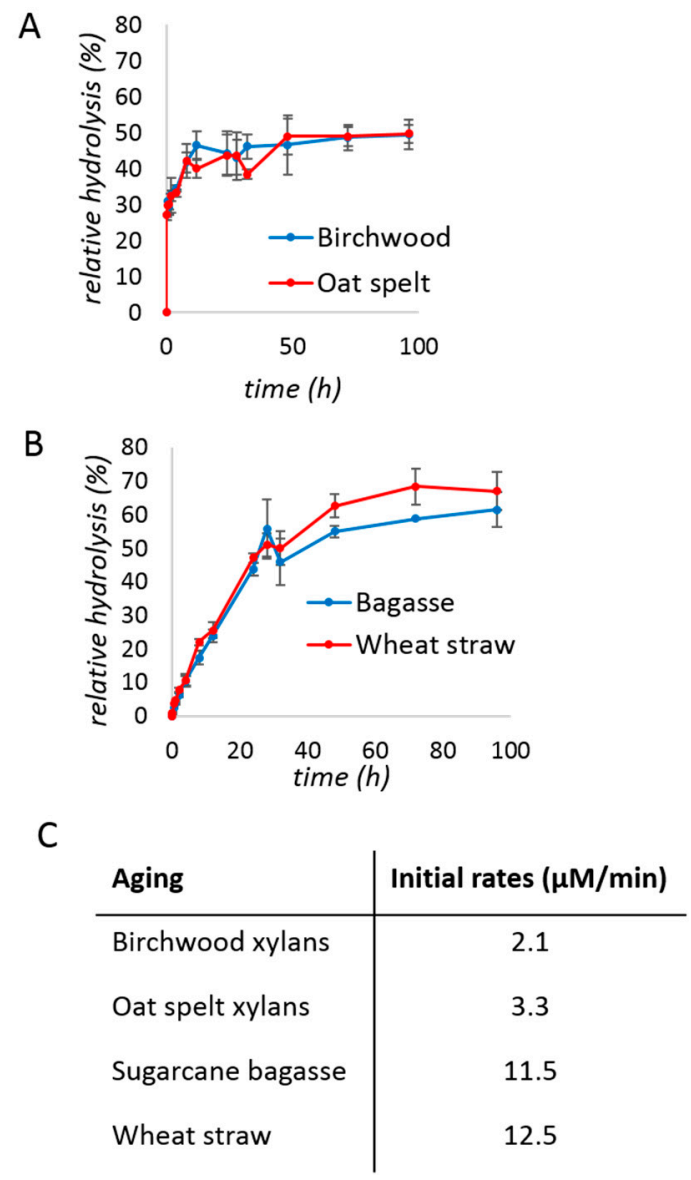

Figure 1. Studies of xylanase kinetics under aging conditions with: (A) birchwood (blue) and oat spelt (red) xylans; (B) sugarcane bagasse (blue) and wheat straw (red). The reaction mixtures of (A) contained $200 \mathrm{mg}$ of xylan, $50 \mathrm{mg}$ of the commercial xylanase mixture (i.e., $0.2 \mathrm{mg}$ of protein or $0.08 \% \mathrm{w} / \mathrm{w}$ ), and $150 \mu \mathrm{L}$ of water. The mixtures of (B) contained $400 \mathrm{mg}$ of substrate, $200 \mathrm{mg}$ of the commercial xylanase mixture (i.e., $0.8 \mathrm{mg}$ of protein or $0.13 \% \mathrm{w} / \mathrm{w}$ ), and $600 \mu \mathrm{L}$ of water. The reaction was milled for $5 \mathrm{~min}$, before transferring to an incubator at $55^{\circ} \mathrm{C}$. (C) Initial rates calculated from the data of panels A and B. The $t=0$ background was subtracted. Reactions were performed in triplicates and the error bar is the standard deviation. 
Under milling only, the xylanase-catalyzed cleavage of birchwood or oat spelt xylans over time was very fast and plateaued rapidly (Figure 2A). As a result, the enzyme loading had to be lowered to $0.02 \%$ protein $(w / w)$ to allow detection of the initial time points. The observed kinetic behavior was again hyperbolic (Figure 2B), but as expected for conditions with less enzyme, the reactions leveled off at lower yields $(<20 \%)$. Based on the initial rates measured, biomass was again a better substrate than purified xylans during milling (Figure 2C,D). Interestingly the initial rate was found to be higher during milling (Figure 2D) than during aging (Figure 1C), but reached a plateau sooner.
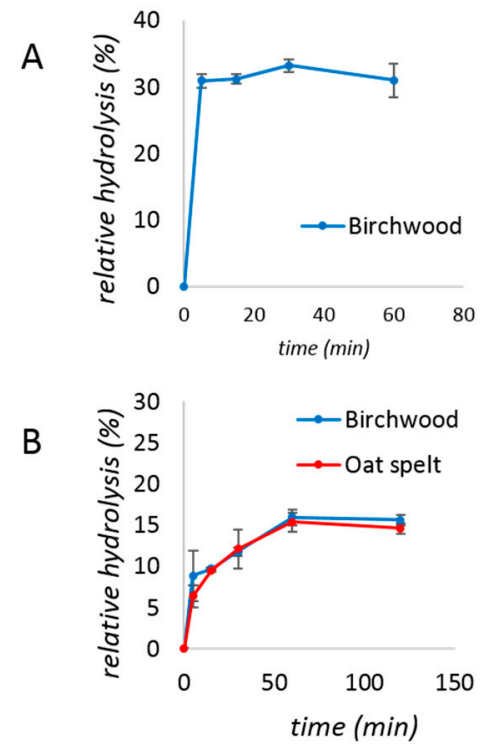

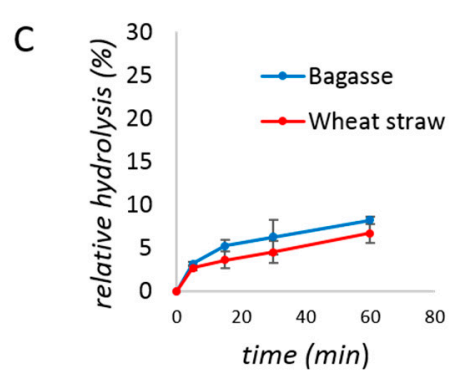

\begin{tabular}{l|c} 
D Milling & Initial rates $(\mu \mathrm{M} / \mathbf{m i n})$ \\
\hline Birchwood xylans & 160 \\
Oat spelt xylans & 120 \\
Sugarcane bagasse & 252 \\
Wheat straw & 213
\end{tabular}

Figure 2. Studies of xylanase reaction kinetics under milling for (A and B) birchwood (blue) and oat spelt (red) xylans, or (C) sugarcane bagasse (blue) and wheat straw (red). (A) the reaction mixture contained $200 \mathrm{mg}$ of birchwood xylan, $500 \mathrm{mg}$ of the commercial xylanase mixture (i.e., $0.2 \mathrm{mg}$ of protein or $0.1 \% w / w$ ), and $150 \mu \mathrm{L}$ of water. (B) the mixtures contained $200 \mathrm{mg}$ of birchwood or oat spelt xylan, $10 \mathrm{mg}$ of the commercial xylanase mixture (i.e., $0.04 \mathrm{mg}$ of protein or $0.02 \% w / w$ ), and $150 \mu \mathrm{L}$ of water. (C) the reaction mixtures contained $400 \mathrm{mg}$ of substrate, $20 \mathrm{mg}$ of the commercial xylanase mixture (i.e., $0.0 .08 \mathrm{mg}$ of protein or $0.02 \% \mathrm{w} / \mathrm{w}$ ), and $600 \mu \mathrm{L}$ of water. (D) Initial rates calculated for the reactions of panels $\mathrm{B}$ and $\mathrm{C}$. Reactions were performed in triplicates and the error bar is the standard deviation.

In previous studies of cellulose digestion by cellulases, it was found that RAging allowed significant improvement of both the rate and the turnover number compared to milling and aging only once [22]. The activity of xylanase $(0.08 \%$ protein $w / w)$ on xylans under RAging conditions, i.e., by repeating 12 one-hour cycles consisting of milling for $5 \mathrm{~min}$ and aging for $55 \mathrm{~min}$, again exhibited a hyperbolic profile, with initial rates of $12-13 \mu \mathrm{M} / \mathrm{min}$, and reached ca. $50 \%$ yield in $12 \mathrm{~h}$ (Figure $3 \mathrm{~A}, \mathrm{C}$ ). The saccharification of biomass during RAging (Figure 3B) was also slower than when milling once and aging. Overall, these results suggest that the optimal milling regime is not universal across different enzymes. 


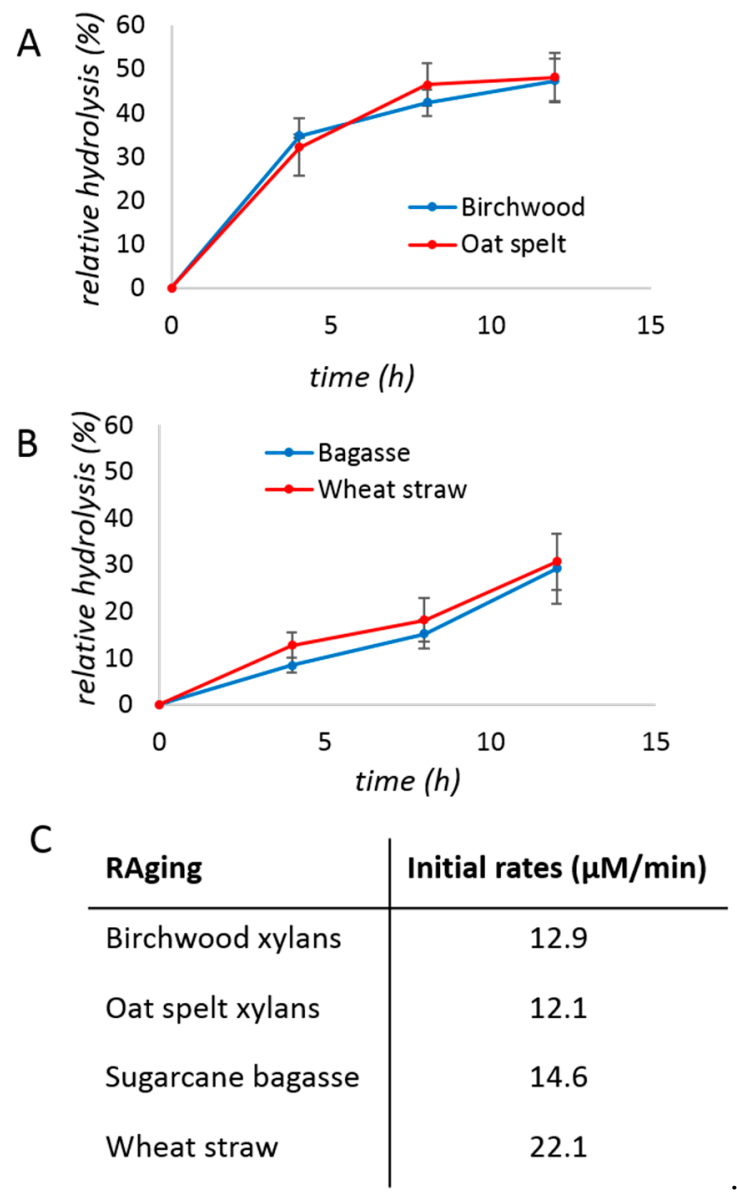

Figure 3. Studies of xylanase reaction kinetics under RAging conditions with (A) birchwood (blue) or oat spelt (red) xylans, or (B) sugarcane bagasse (blue) or wheat straw (red), and the corresponding initial rates (C). (A) the reaction mixtures contained $200 \mathrm{mg}$ of xylan, $50 \mathrm{mg}$ of the commercial xylanase mixture (i.e., $0.2 \mathrm{mg}$ of protein or $0.08 \% w / w)$, and $150 \mu \mathrm{L}$ of water. (B) the reaction mixtures contained $400 \mathrm{mg}$ of substrate, $100 \mathrm{mg}$ of the commercial xylanase mixture (i.e., $0.4 \mathrm{mg}$ of protein or $0.08 \%$ ), and $600 \mu \mathrm{L}$ of water. The reactions were milled for $5 \mathrm{~min}$, before incubating at $55^{\circ} \mathrm{C}$ for $55 \mathrm{~min}$, and repeating this cycle up to 12 times. (C) Initial rates calculated for the reactions of panels A and B. Reactions were performed in triplicates and the error bar is the standard deviation.

Regular sample collection to monitor the reaction may affect reproducibility and progress by altering the temperature and total volume of the reaction mixture in the milling jar over time. The next series of experiments were therefore focused on end-point hydrolysis yields. Reactions using a protein loading of $0.08 \%(w / w)$ revealed that neither $30 \mathrm{~min}$ of milling only, nor $12 \mathrm{~h}$ of RAging (i.e., 12 cycles of repeating a sequence of 5 min milling and 55 min aging), resulted in more than $50 \%$ hydrolysis (Figure 4). The results were similar for both birchwood or oat spelt xylans substrates. Interestingly, treating the xylanase reaction mixture to a $30 \mathrm{~min}$ milling period followed by aging for $72 \mathrm{~h}$ hydrolyzed the xylans with ca. $70 \%$ yield (Figure 4). Taken together, these results suggest that xylanase tolerates well short milling periods and can work efficiently for days under aging conditions. 
A

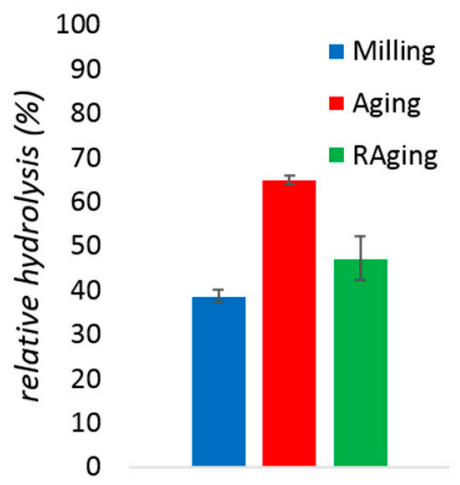

Birchwood

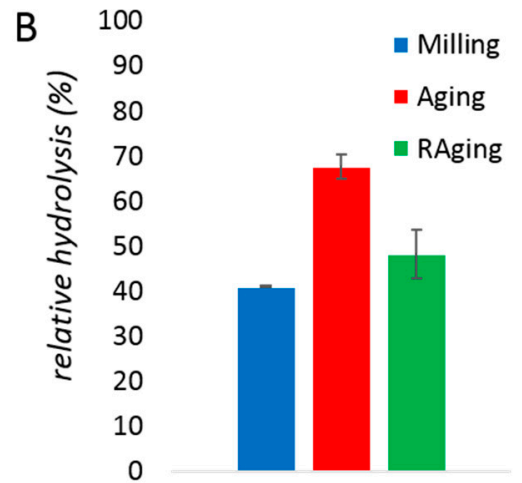

Oat spelt

Figure 4. Progress of enzymatic hydrolysis of birchwood xylan (A) and oat spelt xylan (B) by xylanase after $30 \mathrm{~min}$ of milling (blue), $5 \mathrm{~min}$ of milling followed by $72 \mathrm{~h}$ of aging at $55^{\circ} \mathrm{C}$ (red), or $12 \mathrm{~h}$ of RAging via 12 cycles of $5 \mathrm{~min}$ milling $+55 \mathrm{~min}$ aging (green). The reactions were performed at $0.08 \%$ $w / w$ protein loading on $200 \mathrm{mg}$ of xylan substrate, with $150 \mu \mathrm{L}$ of water $(\eta=0.6 \mu \mathrm{L} / \mathrm{mg})$. Reactions were performed in triplicates and the error bar is the standard deviation.

With biomass, enzymatic hydrolysis after 30 min of milling resulted in $12 \%$ and $8 \%$ yields from sugarcane bagasse and wheat straw, respectively (Figure 5). The conversion during RAging (12 one-hour cycles of milling for $5 \mathrm{~min}$ and aging for $55 \mathrm{~min}$ ) reached hydrolysis yields of $38 \%$ and $36 \%$, for the two biomass samples respectively. Similar to the results obtained with purified xylans, milling followed by aging was more efficient, with yields of $73 \%$ and $84 \%$ obtained for sugarcane bagasse and wheat straw hydrolysis, respectively. Importantly, such high conversions are extremely unusual for xylanase enzymes non-supplemented with cellulases, especially on untreated biomass. Overall, whether the processing method was milling only, a single cycle of milling and aging, or RAging, the initial rate of hydrolysis was lower with purified xylans than with biomass (Figures 1-3), and the enzyme was also active for a longer period of time with biomass, reaching higher yields.

A

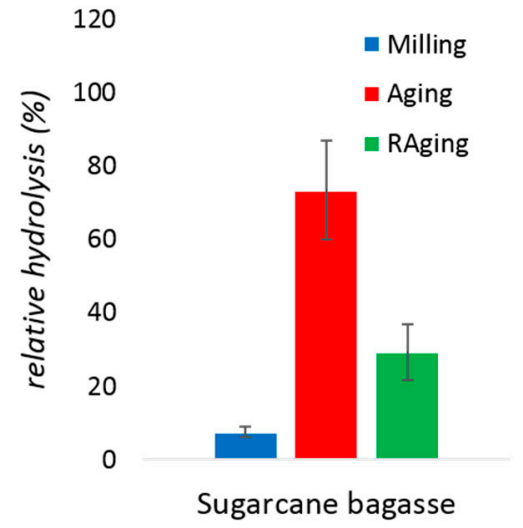

B 120

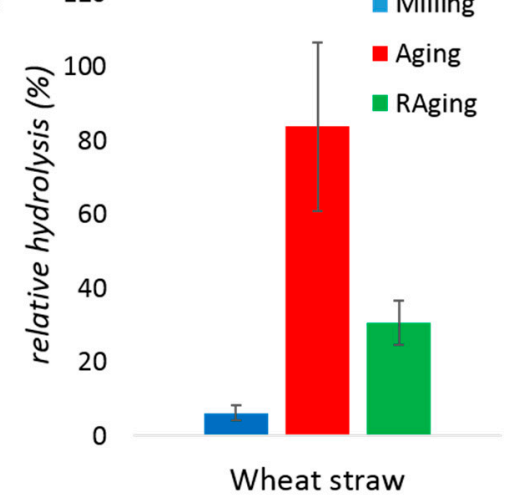

Figure 5. Enzymatic hydrolysis of sugarcane bagasse (A) and wheat straw (B) by xylanase after $30 \mathrm{~min}$ of milling (blue), $30 \mathrm{~min}$ of milling and $72 \mathrm{~h}$ of aging at $55^{\circ} \mathrm{C}$ (red), or $12 \mathrm{~h}$ of RAging via 12 cycles of $5 \mathrm{~min}$ milling $+55 \mathrm{~min}$ aging (green) conditions. The reactions were performed at $0.13 \%(w / w)$ protein loading on $400 \mathrm{mg}$ of substrate, with $600 \mu \mathrm{L}$ of water $(\eta=1 \mu \mathrm{L} / \mathrm{mg})$. Reactions were performed in triplicates and the error bar is the standard deviation.

Chemical analysis of the reaction mixtures to identify the soluble products revealed that, for all substrates, milling and RAging produce mostly oligomers (Figure 6). In contrast, milling and aging only once was found to yield predominantly the xylose monosaccharide and/or disaccharide. Sugar analysis was also performed to quantify the amount of xylose monomer produced (Table S1). When compared to total reducing end yields (DNS assay), the data confirms that xylose is a minor product, 
although highest when milling and aging only once, with soluble oligomers being the major product in all cases. Thus, xylanase is not only more efficient under milling followed by aging, compared to either milling or RAging, but it also generates a cleaner product. This contrasts with the activity of cellulases which was found to be optimal under RAging conditions [29] and suggests that even enzymes of the same family like cellulases and xylanases, both of which are glycoside hydrolases, can have different preferences for optimal activity in the absence of bulk water.

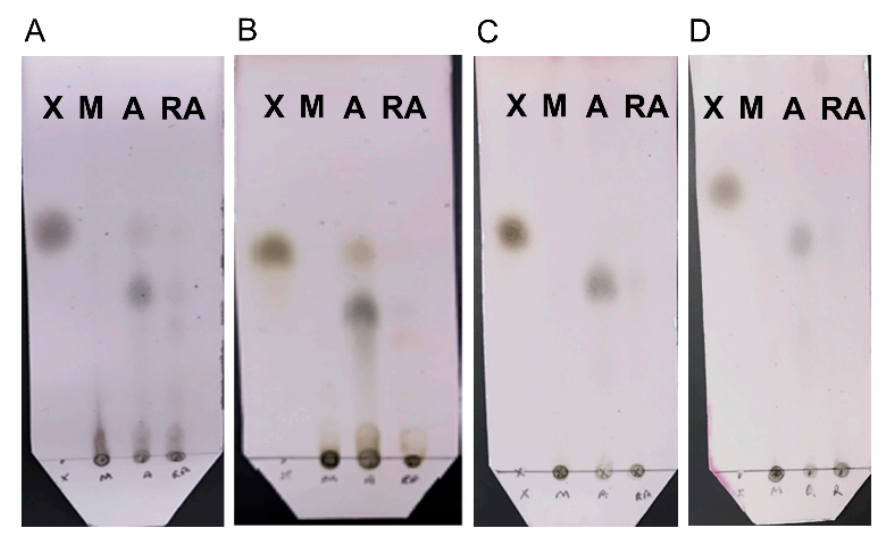

Figure 6. Thin Layer Chromatography (TLC) analysis of the soluble products of enzymatic reactions after 30 min milling (M), 30 min milling and $72 \mathrm{~h}$ aging at $55^{\circ} \mathrm{C}(\mathrm{A})$, or $12 \mathrm{~h}$ RAging via 12 cycles of 5 min milling followed by $55 \mathrm{~min}$ aging (RA), starting from either $200 \mathrm{mg}$ of birchwood (Panel A) or oat spelt (Panel B) xylans hydrolyzed using $0.13 \% w / w$ protein loading at $\eta=1 \mu \mathrm{L} / \mathrm{mg}$, or $400 \mathrm{mg}$ of sugarcane bagasse (Panel C) or wheat straw (Panel D) biomass hydrolyzed with $0.08 \% w / w$ protein at $\eta$ $=0.6 \mu \mathrm{L} / \mathrm{mg}$. Lane $\mathrm{X}$ was loaded with the monosaccharide standard xylose.

Finally, we compared equivalent xylanase reactions with and without bulk water. Both reactions were performed at the same substrate/enzyme ratio, protein content, temperature, and duration, and only differ in the amount of water added. The results (Table 1) are consistent with a larger volume of water (considered standard conditions) being detrimental to xylanase activity. With xylans, the hydrolysis yield dropped by approximately three fold when compared to either 30 min of milling, or milling followed by $72 \mathrm{~h}$ of aging. The difference was most striking with untreated biomass allowed to react for three days, with the yield dropping from ca. $79 \%$ to ca. $5 \%$ with added bulk water. These results strongly suggest that solvent-less conditions can offer a more suitable platform for optimal performance of xylanase.

Table 1. Comparison of the percent hydrolysis yield (based on the DNS assay) of xylanase reactions on different substrates in the presence or absence of bulk water. In both cases, $100 \mathrm{mg}$ of substrate was used, with $125 \mu \mathrm{L}$ or $10 \mathrm{~mL}$ of water, and xylanase at a protein loading of $0.08 \% w / w$.

\begin{tabular}{ccccc}
\hline & \multicolumn{2}{c}{ No Bulk Water } & \multicolumn{2}{c}{ With Bulk Water } \\
\cline { 2 - 5 } & Milling $\mathbf{3 0} \mathbf{~ m i n}, \mathbf{R T}$ & Aging $\mathbf{7 2} \mathbf{h}, \mathbf{5 5}{ }^{\circ} \mathbf{C}$ & Shaking $\mathbf{3 0} \mathbf{~ m i n}, \mathbf{R T}$ & Shaking $\mathbf{7 2} \mathbf{~ h , ~} \mathbf{5 5}{ }^{\circ} \mathbf{C}$ \\
\hline Birchwood xylan & $39 \pm 1 \%$ & $65 \pm 1 \%$ & $14 \pm 1 \%$ & $24 \pm 3 \%$ \\
Oat spelt xylan & $41 \pm 1 \%$ & $68 \pm 3 \%$ & $14 \pm 1 \%$ & $26 \pm 1 \%$ \\
Sugarcane bagasse & $12 \pm 6 \%$ & $73 \pm 14 \%$ & $1.6 \pm 0.5 \%$ & $4 \pm 1 \%$ \\
Wheat straw & $8 \pm 4 \%$ & $84 \pm 23 \%$ & $2.4 \pm 0.2 \%$ & $5 \pm 2 \%$ \\
\hline
\end{tabular}

\section{Materials and Methods}

\subsection{Substrates, Enzyme, and Equipment}

Birchwood xylan ( $\geq 90 \%$, now discontinued) and oat spelt xylan ( $\geq 70 \%$, now discontinued) were purchased from Sigma-Aldrich (Missouri, MO, USA). The untreated sugarcane bagasse and wheat straw samples were provided and their contents analyzed by Iogen Corporation (Ottawa, Canada). 
Xylanase from T. lanuginosus was purchased as a lyophilized powder of $2798 \mathrm{U} / \mathrm{g}$ from Sigma-Aldrich (Missouri, MO, USA). Analysis of this commercial preparation using the Bradford assay revealed a protein content of only $\sim 0.4 \%$, with the rest likely consisting of buffer, lyoprotectants and/or growth medium. The sugars contained in this matrix were quantified using the DNS assay and this amount was subtracted from reaction product measurements. All the reagents used in experimental section were of practical grade. Ball milling was conducted in a FTS 1000 shaker mill from Form Tech Scientific (Montreal, QC, Canada). Absorption was measured on a plate reader SpectraMax i3x from Molecular Device (San Jose, CA, USA).

\subsection{SDS-Page Gel Analysis}

Denatured protein solution $(15 \mu \mathrm{L}$ of a $4 \mathrm{mg} / \mathrm{mL}$ solution in $50 \mathrm{mM}$ sodium acetate buffer, $\mathrm{pH} 5$, boiled for $10 \mathrm{~min}$ ) containing an elution marker was deposited in a well of a pre-cast gel Miniprotean TGX 4-20\% acrylamide from BIO-RAD. The SDS-PAGE was run for ca. $40 \mathrm{~min}$ with a constant voltage of $150 \mathrm{~V}$ in a Tris/Glycine/SDS buffer. After completion, the gel was stained with a Coomassie blue $(0.25 \% w / v)$ solution in water/MeOH/AcOH $(5: 4: 1 \mathrm{v} / v / v)$ for $15 \mathrm{~min}$. It was then de-stained using a mixture of water/MeOH/AcOH (5:4:1 v/v/v) for one hour. It was further de-stained overnight in water. Protein weight are characterized compared to a protein ladder (LMW calibration kit from GE).

\subsection{Relative Hydrolysis}

The reaction yields were first estimated using the classical dinitrosalicylic acid method [40]. DNS reacts with the reducing end of sugars and does not discriminate between them. Detailed sugar analysis (see Section 3.4) was performed on key samples to determine specific xylose concentrations and yields. The DNS reagent was prepared according to Miller [42] with the following modifications: DNS $(1 \mathrm{~g})$, potassium sodium tartrate $(30 \mathrm{~g})$, and water $(50 \mathrm{~mL})$, and $\mathrm{NaOH}(20 \mathrm{~mL}$ of a $2 \mathrm{M}$ solution) were mixed before diluting to $100 \mathrm{~mL}$ in water. The solution was filtered through cotton and stored at $4{ }^{\circ} \mathrm{C}$ for up to one month. The DNS solution was calibrated using D-xylose dissolved in water over a range of 0.2 to $1.0 \mathrm{mg} / \mathrm{mL}$. For measuring the concentration of reducing sugars, aliquots $(\sim 15 \mathrm{mg})$ were suspended in ice cold water to a final xylan concentration of $10 \mathrm{mg} / \mathrm{mL}$ as determined by the Equation (1):

$$
V=0.1 \times m_{\text {xylan } /}\left(m_{\text {total }} \times m_{\text {sample }}\right)
$$

The $m_{\text {xylan }}$ is defined as the mass of xylan that was added to the milling jar, the mass total $_{\text {is defined }}$ as the total mass of all reagents (water included) added into the milling jar, and the $\mathrm{m}_{\text {sample }}$ is the mass of the aliquot taken from the milling jar. $\mathrm{V}$ is defined as the volume of water that should be added to reach a final xylan concentration of $10 \mathrm{mg} / \mathrm{mL}$. The microcentrifuge tubes containing the suspension of the mixture from the solvent-free reactions in ice-cold water were immediately placed into a boiling water bath for $30 \mathrm{~min}$ to inactivate the enzymes. For in-solution enzymatic reactions, aliquots collected in a microcentrifuge tube were directly boiled by immersion in a boiling water bath. Once cooled, the samples from the solvent-free reactions were disturbed and broken down to small pieces with a spatula and centrifuged at $21,100 \times g$ for $5 \mathrm{~min}$ to pellet any insoluble material. The supernatant was used to measure the amount of reducing sugar using the DNS reagent. The supernatant $(200 \mu \mathrm{L}$, diluted $4 \times)$ was added to the DNS solution $(100 \mu \mathrm{L})$, and was boiled for $5 \mathrm{~min}$. Then, $200 \mu \mathrm{L}$ was transferred into the well of a clear-bottom 96-well microtiter plate. Absorbance was measured at $540 \mathrm{~nm}$ using a Molecular Devices SpectraMax i3x (San Jose, California, USA) microplate reader with pathcheck enabled. Yields were calculated on a dry mass basis by approximating hemicellulose to linear infinite chains of linked xylose.

\subsection{Sugar Analysis}

The monosaccharides were analyzed in a sugar analyzer (YSI 2900, Yellow Spring Instruments (Yellow Spings, OH, USA). Lyophilized pellets were weighed (1-12 mg) and suspended in distilled 
water $(100 \mu \mathrm{L})$. The samples were vortexed for $30 \mathrm{~s}$, kept at $30^{\circ} \mathrm{C}$ for $30 \mathrm{~min}$ to allow for full sugar dissolution, and vortexed again for $30 \mathrm{~s}$. Next, the mixtures were centrifuged for 5 min at $9391 \times g$, and the supernatant was separated and analyzed. This analyzer uses glucose and xylose specific membranes, and calibrates itself automatically with standard glucose $(2.5 \mathrm{~g} / \mathrm{L})$ and xylose $(20 \mathrm{~g} / \mathrm{L})$ solutions. The $\mathrm{pH}$ was kept at 7.0 by using a mono and dibasic sodium phosphate buffer (YSI 2357, $0.1 \mathrm{M}, \mathrm{pH} 7.0)$.

\subsection{Pre-Milling of Biomass}

$1.5 \mathrm{~g}$ of raw sugarcane bagasse or wheat straw was introduced in a $30 \mathrm{~mL}$ stainless steel milling jar with two stainless steel balls of $10 \mathrm{~mm}$ diameter. The jar was then shaken at $30 \mathrm{~Hz}$ for $10 \mathrm{~min}$ to afford a fine powder which was kept in room conditions.

\subsection{Determination of Optimal Water Loading}

Birchwood and oat xylan (200 mg), and xylanase (50 mg of the commercial preparation) were introduced into a $10 \mathrm{~mL}$ volume teflon jar, along with two stainless steel balls of $7 \mathrm{~mm}$ diameter each. Then, $50 \mu \mathrm{L}, 100 \mu \mathrm{L}, 150 \mu \mathrm{L}$, or $200 \mu \mathrm{L}$ water was added to the mixture before milling at $30 \mathrm{~Hz}$ and room temperature for $30 \mathrm{~min}$. The samples were analyzed for reducing end sugars using the DNS protocol described above.

With sugarcane bagasse or wheat straw, the substrate $(400 \mathrm{mg})$, xylanase (200 $\mathrm{mg}$ of the commercial preparation) were added to a $10 \mathrm{~mL}$ volume teflon jar, along with two stainless steel balls of $7 \mathrm{~mm}$ diameter each. Then, $360 \mu \mathrm{L}, 600 \mu \mathrm{L}$, or $720 \mu \mathrm{L}$ of water was added to the mixture before milling at $30 \mathrm{~Hz}$ and room temperature for $30 \mathrm{~min}$. The samples were analyzed for reducing end sugars using the DNS protocol described above.

\subsection{TLC Analysis of the Soluble Enzymatic Reaction Products}

TLC analysis was performed with $60 \AA$ silica gel TLC plates (F-254) from Silicycle, using chloroform/acetic acid/ $\mathrm{H}_{2} \mathrm{O}$ (6:7:1) as the eluent. The eluted TLC plates were stained with a solution of $p$-anisaldehyde (15 g of $p$-anisaldehyde, $250 \mathrm{~mL}$ of ethanol and $2.5 \mathrm{~mL}$ of conc. sulfuric acid), followed by heating with a blow dryer until completely dry.

\subsection{Reactions in Solution}

Birchwood and oat xylans (100 mg) and xylanase (25 $\mathrm{mg}$ of the commercial preparation) were mixed in water $(10 \mathrm{~mL})$ in a $50 \mathrm{~mL}$ tube. With sugarcane bagasse or wheat straw, the substrate $(100 \mathrm{mg})$ and xylanase $(50 \mathrm{mg})$ were mixed in water $(10 \mathrm{~mL})$ in a $50 \mathrm{~mL}$ tube. Each reaction was allowed to proceed on a rotary shaker $(400 \mathrm{rpm})$ at room temperature for $30 \mathrm{~min}$, in order to match the conditions of solvent-free milling, or at $55^{\circ} \mathrm{C}$ for $72 \mathrm{~h}$ to match the conditions of solvent-free milling and aging. Reaction aliquots were stored at $-20^{\circ} \mathrm{C}$ until analysis.

\section{Conclusions}

Many attempts have been made over the past decades to reduce the cost and increase the efficacy of enzymatic hemicellulose hydrolysis [46]. These efforts have mainly focused on identification and engineering of novel enzymes $[19,21,47]$, or accessory proteins $[3,48]$. In parallel, researchers have also worked at optimizing biomass pre-treatment methods to improve enzymatic reaction yields [49]. We propose here a starkly different strategy inspired from the natural environment of xylanases. Our unconventional method consists of briefly milling a mixture of lyophilized enzyme preparation, solid substrate, and several equivalents of water, before allowing the resulting moist solid to sit under controlled conditions (i.e., aging). Besides improving the yields compared to the same enzymatic reaction performed in dilute buffer, this unique process does not require any harsh chemicals, and greatly decreases the overall reaction volume, therefore facilitating handling of the mixture, and 
generating significantly less waste. Importantly, this enzymatic method proceeds with yields $>70 \%$ at very low protein loading $(0.08 \% w / w)$, without the need for biomass pre-treatment.

Supplementary Materials: The following are available online at http://www.mdpi.com/1420-3049/24/23/4206/s1, Figure S1: SDS-PAGE analysis (0.1\% SDS (w/v), $25 \mathrm{mM}$ Tris) of commercial xylanase from Thermomycec lanuginosus., Figure S2: Optimization of the amount of water (reported as $\eta$, i.e., the volume of water added over the total amount of solid in $\mu \mathrm{L} / \mathrm{mg}$ ) for the hydrolysis of purified birchwood (A) or oat spelt (B) xylan by xylanase under milling conditions., Figure S3: Optimization of the amount of water (reported as $\eta$, i.e., the volume of water added over the total amount of solid in $\mu \mathrm{L} / \mathrm{mg}$ ) for the hydrolysis of sugarcane bagasse (A) or wheat straw (B)., Figure S4: Optimization of the enzyme loading for the hydrolysis of birchwood xylan, oat spelt xylan, sugarcane bagasse or wheat straw by xylanase under milling only $(30 \mathrm{~min})$ or milling $(30 \mathrm{~min})$ followed by aging $(72 \mathrm{~h}$ at $\left.55^{\circ} \mathrm{C}\right)$., Figure S5: Effect of milling frequency $(10 \mathrm{~Hz}$ or $30 \mathrm{~Hz})$ on the xylanase-catalyzed hydrolysis of oat spelt xylan. Table S1: Results of sugar analyses.

Author Contributions: Conceptualization, T.F., K.A., S.O., F.H.; methodology, K.A., T.F., F.H., S.O.; formal analysis, S.O., K.D.; investigation, S.O., F.H.; writing—original draft preparation, S.O.; writing-review and editing, K.A., T.F., S.O., F.H., M.-J.D., K.D.; supervision, K.A., T.F., M.-J.D.; project administration, K.A., T.F.; funding acquisition, K.A., T.F.

Funding: This work was funded by GreenCentre Canada IHC4 Award (grant no. G16-21), FRQNT Team Grant (grant no. FRQ-NT PR-254169), NSERC Discovery Grant (grants no. RGPIN-2017-04107 and RGPIN-2017-06467), Idea-to-Innovation (I2I grant no. 508646).

Acknowledgments: The FRQNT Center in Green Chemistry \& Catalysis (CCVC/CGCC; grant no. FRQNT-2020-RS4-265155-CCVC) is acknowledged for support. Sugarcane bagasse and wheat straw were kindly provided by Iogen Corporation (Ottawa, ON) who also performed the content analysis of the samples.

Conflicts of Interest: Some of the herein presented work is a part of the patent application US 62/465,443 filed on 1 March 2017. TF is a co-founder of Form-Tech Scientific, which has provided some of the equipment used in this study.

\section{References}

1. Kirk, R.E.; Othmer, D. Encyclopedia of Chemical Technology, 5th ed.; John Wiley \& Sons, Inc.: Hoboken, NJ, USA, 2007.

2. Morgan, H.M., Jr.; Bu, Q.; Liang, J.; Liu, Y.; Mao, H.; Shi, A.; Lei, H.; Ruan, R. A review of catalytic microwave pyrolysis of lignocellulosic biomass for value-added fuel and chemicals. Bioresour. Technol. 2017, 230, 112-121. [CrossRef]

3. Horn, S.J.; Vaaje-Kolstad, G.; Westereng, B.; Eijsink, V. Novel enzymes for the degradation of cellulose. Biotechnol. Biofuels 2012, 5, 45. [CrossRef] [PubMed]

4. Prade, R.A. Xylanases: From biology to biotechnology. Biotechnol. Genet. Eng. Rev. 1995, 13, $101-132$. [CrossRef] [PubMed]

5. Shallom, D.; Shoham, Y. Microbial hemicellulases. Curr. Opin. Microbiol. 2003, 6, 219-228. [CrossRef]

6. Hilpmann, G.; Becher, N.; Pahner, F.A.; Kusema, B.; Mäki-Arvela, P.; Lange, R.; Murzin, D.Y.; Salmi, T. Acid hydrolysis of xylan. Catal. Today 2016, 259, 376-380. [CrossRef]

7. Larsson, S.; Palmqvist, E.; Hahn-Hägerdal, B.; Tengborg, C.; Stenberg, K.; Zacchi, G.; Nilvebrant, N.O. The generation of fermentation inhibitors during dilute acid hydrolysis of softwood. Enzyme Microb. Technol. 1999, 24, 151-159. [CrossRef]

8. Luo, C.; Brink, D.L.; Blanch, H.W. Identification of potential fermentation inhibitors in conversion of hybrid poplar hydrolysate to ethanol. Biomass Bioenergy 2002, 22, 125-138. [CrossRef]

9. Jönsson, L.J.; Martín, C. Pretreatment of lignocellulose: Formation of inhibitory by-products and strategies for minimizing their effects. Bioresour. Technol. 2016, 199, 103-112. [CrossRef]

10. Dietrich, K.; Dumont, M.J.; Schwinghamer, T.; Orsat, V.; Del Rio, L.F. Model study to assess softwood hemicellulose hydrolysates as the carbon source for PHB production in Paraburkholderia sacchari IPT 101. Biomacromolecules 2018, 19, 188-200. [CrossRef]

11. Kucera, D.; Benesova, P.; Ladicky, P.; Pekar, M.; Sedlacek, P.; Obruca, S. Production of polyhydroxyalkanoates using hydrolysates of spruce sawdust: Comparison of hydrolysates detoxification by application of overliming, active carbon, and lignite. Bioengineering 2017, 4, 53. [CrossRef] 
12. Canilha, L.; Chandel, A.K.; Suzane dos Santos Milessi, T.; Antunes, F.A.F.; Luiz da Costa Freitas, W.; das Graças Almeida Felipe, M.; da Silva, S.S. Bioconversion of sugarcane biomass into ethanol: An overview about composition, pretreatment methods, detoxification of hydrolysates, enzymatic saccharification, and ethanol fermentation. J. Biomed. Biotecnol. 2012. [CrossRef] [PubMed]

13. Pan, W.; Perrotta, J.A.; Stipanovic, A.J.; Nomura, C.T.; Nakas, J.P. Production of polyhydroxyalkanoates by Burkholderia cepacia ATCC 17759 using a detoxified sugar maple hemicellulosic hydrolysate. J. Ind. Microbiol. Biotechnol. 2012, 39, 459-469. [CrossRef] [PubMed]

14. Janusz, G.; Pawlik, A.; Sulej, J.; Świderska-Burek, U.; Jarosz-Wilkołazka, A.; Paszczyński, A. Lignin degradation: Microorganisms, enzymes involved, genomes analysis and evolution. FEMS Microbiol. Rev. 2017, 41, 941-962. [CrossRef] [PubMed]

15. Polizeli, M.L.T.M.; Rizzatti, A.C.S.; Monti, R.; Terenzi, H.F.; Jorge, J.A.; Amorim, D.S. Xylanases from fungi: Properties and industrial applications. Appl. Microbiol. Biotechnol. 2005, 67, 577-591. [CrossRef]

16. Collins, T.; Gerday, C.; Feller, G. Xylanases, xylanase families and extremophilic xylanases. FEMS Microbiol. Rev. 2005, 29, 3-23. [CrossRef]

17. Zhang, J.; Siika-aho, M.; Puranen, T.; Tang, M.; Tenkanen, M.; Viikari, L. Thermostable recombinant xylanases from Nonomuraea flexuosa and Thermoascus aurantiacus show distinct properties in the hydrolysis of xylans and pretreated wheat straw. Biotechnol. Biofuels 2011, 4, 12. [CrossRef]

18. Wang, K.; Cao, R.; Wang, M.; Lin, Q.; Zhan, R.; Xu, H.; Wang, S. A novel thermostable GH10 xylanase with activities on a wide variety of cellulosic substrates from a xylanolytic Bacillus strain exhibiting significant synergy with commercial Celluclast $1.5 \mathrm{~L}$ in pretreated corn stover hydrolysis. Biotechnol. Biofuels 2019, 12, 48. [CrossRef]

19. Patipong, T.; Lotrakul, P.; Padungros, P.; Punnapayak, H.; Bankeeree, W.; Prasongsuk, S. Enzymatic hydrolysis of tropical weed xylans using xylanase from Aureobasidium melanogenum PBUAP46 for xylooligosaccharide production. 3 Biotech 2019, 9, 56. [CrossRef]

20. Zhuo, R.; Yu, H.; Qin, X.; Ni, H.; Jiang, Z.; Ma, F.; Zhang, X. Heterologous expression and characterization of a xylanase and xylosidase from white rot fungi and their application in synergistic hydrolysis of lignocellulose. Chemosphere 2018, 212, 24-33. [CrossRef]

21. Liu, X.; Liu, Y.; Jiang, Z.; Liu, H.; Yang, S.; Yan, Q. Biochemical characterization of a novel xylanase from Paenibacillus barengoltzii and its application in xylooligosaccharides production from corncobs. Food Chem. 2018, 264, 310-318. [CrossRef]

22. Hernández, J.G.; Frings, M.; Bolm, C. Mechanochemical enzymatic kinetic resolution of secondary alcohols under ball-milling conditions. ChemCatChem. 2016, 8, 1769-1772. [CrossRef]

23. Hernández, J.G.; Ardila-Fierro, K.J.; Crawford, D.; James, S.L.; Bolm, C. Mechanoenzymatic peptide and amide bond formation. Green Chem. 2017, 19, 2620-2625. [CrossRef]

24. Ardila-Fierro, K.J.; Crawford, D.E.; Körner, A.; James, S.L.; Bolm, C.; Hernández, J.G. Papain-catalysed mechanochemical synthesis of oligopeptides by milling and twin-screw extrusion: Application in the Juliá-Colonna enantioselective epoxidation. Green Chem. 2018, 20, 1262-1269. [CrossRef]

25. Hernández, J.G.; Turberg, M.; Schiffers, I.; Bolm, C. Mechanochemical Strecker reaction: Access to $\alpha$-aminonitriles and tetrahydroisoquinolines under ball-milling conditions. Chem. Eur. J. 2016, 22, 14513-14517. [CrossRef] [PubMed]

26. Pérez-Venegas, M.; Reyes-Rangel, G.; Neri, A.; Escalante, J.; Juaristi, E. Mechanochemical enzymatic resolution of $N$-benzylated- $\beta 3$-amino esters. Beilstein J. Org. Chem. 2017, 13, 1728-1734. [CrossRef] [PubMed]

27. Pérez-Venegas, M.; Juaristi, E. Mechanoenzymatic resolution of racemic chiral amines, a green technique for the synthesis of pharmaceutical building blocks. Tetrahedron 2018, 74, 6453-6458. [CrossRef]

28. Bolm, C.; Hernández, J.G. From synthesis of amino acids and peptides to enzymatic catalysis: A bottom-up approach in mechanochemistry. ChemSusChem. 2018, 11, 1410-1420. [CrossRef]

29. Hammerer, F.; Loots, L.; Do, J.L.; Therien, J.D.; Nickels, C.W.; Friščić, T.; Auclair, K. Solvent-free enzyme activity: Quick, high-yielding mechanoenzymatic hydrolysis of cellulose into glucose. Angew. Chem. 2018, 130, 2651-2654. [CrossRef]

30. Hammerer, F.; Ostadjoo, S.; Friščić, T.; Auclair, K. Controlling the reactivity of enzymes in mechanochemistry: Inert surfaces protect $\beta$-glucosidase activity during ball milling. ChemSusChem 2019. [CrossRef]

31. Therien, J.P.D.; Hammerer, F.; Friščić, T.; Auclair, K. Mechanoenzymatic breakdown of chitinous material to $\mathrm{N}$-acetylglucosamine: The benefits of a solvent-less environment. ChemSusChem 2019, 12, 3481-3490. 
32. Kaabel, S.; Friščić, T.; Auclair, K. Mechanoenzymatic transformations in the absence of bulk water - A more natural way of using enzymes. ChemBioChem 2019. [CrossRef] [PubMed]

33. Baláž, P.; Achimovičová, M.; Baláž, M.; Billik, P.; Cherkezova-Zheleva, Z.; Criado, J.M.; Delogu, F.; Dutková, E.; Gaffet, E.; Gotor, F.J.; et al. Hallmarks of mechanochemistry: From nanoparticles to technology. Chem. Soc. Rev. 2013, 42, 7571-7637. [CrossRef] [PubMed]

34. James, S.L.; Adams, C.J.; Bolm, C.; Braga, D.; Collier, P.; Friščić, T.; Grepioni, F.; Harris, K.D.; Hyett, G.; Jones, W.; et al. Mechanochemistry: Opportunities for new and cleaner synthesis. Chem. Soc. Rev. 2012, 41, 413-447. [CrossRef] [PubMed]

35. Do, J.-L.; Friščić, T. Mechanochemistry: A Force of Synthesis. ACS Centr. Sci. 2017, 3, 13-19. [CrossRef] [PubMed]

36. Colacino, E.; Carta, M.; Pia, G.; Porcheddu, A.; Ricci, P.C.; Delogu, F. Processing and investigation methods in mechanochemical kinetics. ACS Omega 2018, 3, 9196-9209. [CrossRef]

37. Cliffe, M.J.; Mottillo, C.; Stein, R.S.; Bučar, D.K.; Friščić, T. Accelerated aging: A low energy, solvent-free alternative to solvothermal and mechanochemical synthesis of metal-organic materials. Chem. Sci. 2012, 3, 2495-2500. [CrossRef]

38. Mottillo, C.; Friščić, T. Advances in solid-state transformations of coordination bonds: From the ball mill to the aging chamber. Molecules 2017, 22, 144. [CrossRef]

39. Kelsey, R.G.; Shafizadeh, F. Enhancement of cellulose accessibility and enzymatic hydrolysis by simultaneous wet milling. Biotechnol. Bioeng. 1980, 22, 1025-1036. [CrossRef]

40. Mais, U.; Esteghlalian, A.R.; Saddler, J.N.; Mansfield, S.D. Enhancing the enzymatic hydrolysis of cellulosic materials using simultaneous ball milling. App. Biochem. Biotechnol. 2002, 98-100, 815-832. [CrossRef]

41. Hasa, D.; Miniussi, E.; Jones, W. Mechanochemical synthesis of multicomponent crystals: One liquid for one polymorph? A myth to dispel. Cryst. Growth Des. 2016, 16, 4582-4588. [CrossRef]

42. Friščić, T.; Childs, S.L.; Rizvi, S.A.; Jones, W. The role of solvent in mechanochemical and sonochemical cocrystal formation: A solubility-based approach for predicting cocrystallisation outcome. CrystEngComm. 2009, 11, 418-426. [CrossRef]

43. Hasa, D.; Jones, W. Screening for new pharmaceutical solid forms using mechanochemistry: A practical guide. Adv. Drug Deliv. Rev. 2017, 117, 147-161. [CrossRef] [PubMed]

44. Singh, S.; Madlala, A.M.; Prior, B.A. Thermomyces lanuginosus: Properties of strains and their hemicellulases. FEMS Microbiol. Rev. 2003, 27, 3-16. [CrossRef]

45. Miller, G.L. Use of dinitrosalicylic acid reagent for determination of reducing sugar. Anal. Chem. 1959, 31, 426-428. [CrossRef]

46. Taherzadeh, M.J.; Karimi, K. Enzyme-based hydrolysis processes for ethanol from lignocellulosic materials: A review. BioResources 2007, 2, 707-738.

47. Romero-Fernández, M.; Moreno-Perez, S.; Orrego, A.H.; de Oliveira, S.M.; Santamaría, R.I.; Díaz, M.; Guisan, J.M.; Rocha-Martin, J. Designing continuous flow reaction of xylan hydrolysis for xylooligosaccharides production in packed-bed reactors using xylanase immobilized on methacrylic polymer-based supports. Bioresour. Technol. 2018, 266, 249-258. [CrossRef]

48. Zhang, Y.; Yang, H.; Yu, X.; Kong, H.; Chen, J.; Luo, H.; Bai, Y.; Yao, B. Synergistic effect of acetyl xylan esterase from Talaromyces leycettanus JCM12802 and xylanase from Neocallimastix patriciarum achieved by introducing carbohydrate-binding module-1. AMB Express 2019, 9, 13. [CrossRef]

49. Wi, S.G.; Cho, E.J.; Lee, D.S.; Lee, S.J.; Lee, Y.J.; Bae, H.J. Lignocellulose conversion for biofuel: A new pretreatment greatly improves downstream biocatalytic hydrolysis of various lignocellulosic materials. Biotechnol. Biofuels 2015, 8, 228. [CrossRef]

Sample Availability: Samples of the compounds are available from the authors. 